DOIf $10.24060 / 2076-3093-2017-7-4-48-52$

ОПЫТ ЛАПАРОСКОПИЧЕСКОЙ ХИРУРГИИ ПРИ ЛЕЧЕНИИ ПОЧЕЧНО-КЛЕТОЧНОГО РАКА НА БАЗЕ РЕСПУБЛИКАНСКОГО КЛИНИЧЕСКОГО ОНКОЛОГИЧЕСКОГО ДИСПАНСЕРА

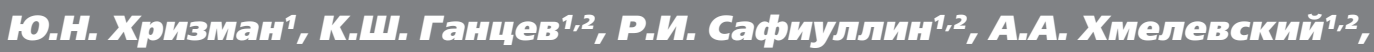

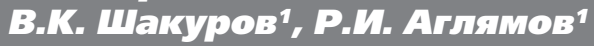

1Республиканский клинический онкологический диспансер, Россия, 450054,

Уфа, проспект Октября, 73/1

2Башкирский государственный медицинский университет, Россия, 450008, Уфа, ул. Ленина, 3

Хризман Юрий Нусинович - К.М.Н., заведующий

урологическим отделением №7 РКОД, врач онколог-уролог,

e-mail:khrizmanyui@onkorb.ru

Ганцев Камиль Шамильевич - д.м.Н., профессор кафедры

онкологии ФГБОУ ВО БГМУ Минздрава России, врач онколог

урологического отделения №7РКОД, e-mail: gantseff@mail.ru

Сафиуллин Руслан Ильясович - Д.М.Н., профессор кафедры

урологии ФГБОУ ВО БГМУ Минздрава России, врач онколог-уро-

лог урологического отделения №7 РКОД,

e-mail: russafiullin@rambler.ru

Хмелевский Андрей Анатольевич - аспирант кафедры

онкологИи ФГБОУ ВО БГМУ Минздрава России, врач онколог

урологического отделения №7 РКОД, e-mail: larotos@mail.ru

Шакуров Валерий Камильевич - врач онколог урологического

отделения №7 РКОД, e-mail: hakurovv@rambler.ru

Аглямов Раушан Ильясович - врач онколог-уролог урологичес-

кого отделения №7 РКОД, e-mail: au-aglymov@yandex.ru

Контакты: Хмелевский Андрей Анатольевич,

e-mail: larotos@mail.ru

Введение. Цель исследования - изучение ближайших результатов лапароскопи ческих операций у пациентов с локализованным почечно-клеточным раком.

Материалы и методы. Проанализированы и оценены результаты лечения 92 пациентов, прооперированных с 2015 по 2017 гг. с помощью лапароскопической техники по поводу почечно-клеточного рака. Из них 57 мужчин (62\%) и 35 женщин (38\%), средний возраст 50,5 2,25 года (min 26 и тах 75 лет).

Результаты. На продолжительность операции влияли различные факторы, такие как особенности сосудистой анатомии почек, наличие спаечного процесса брюшной полости, состояние паранефральной жировой клетчатки. При совершенствовании техники выполнения лапароскопических вмешательств время операции значительно сократилось. В период освоения методики лапароскопических вмешательств на почке время операции в среднем составляло 210,0土20,2 мин (min 120 и max 300 мин),

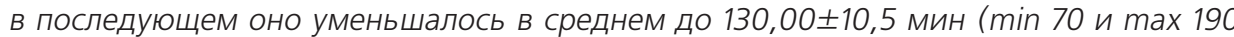
мин). После накопления опыта была освоена методика лапароскопической резекции почки без тотальной ишемии с селективным пережатием сегментарных артерий или без компрессии почечной артерии.

Заключение. Анализ ближайших результатов лапароскопических вмешательств у пациентов с почечно-клеточным раком показал их высокую эффективность и безопасность. Результаты лапароскопических нефрэктомий и резекций почки существенно улучшаются с совершенствованием технологий и накоплением хирургического опыта.

Ключевые слова: нефрэктомия, лапароскопия, лапароскопическая резекция почки, почек новообразования

Для цитирования: Хризман Ю.Н., Ганцев К.Ш., Сафиуллин Р.И., Хмелевский А.А., Шакуров В.К., Аглямов Р.И. Опыт лапароскопической хирургии при лечении почечно-клеточного рака на базе Республиканского клинического онкологического диспансера. Креативная хирургия и онкология. 2017;7(4): 48-52. DOI:10.24060/20763093-2017-7-4-48-52 


\title{
EXPERIENCE OF LAPAROSCOPIC SURGERY IN THE TREATMENT OF RENAL CELL CANCER ON THE BASIS OF THE REPUBLICAN CLINICAL ONCOLOGICAL DISPENSARY
}

\author{
Yuriy N. Khrizman', Kamil Sh. Gantsev ${ }^{1,2}$, Ruslan I. Safiullin',2, \\ Andrey A. Khmelevsky1,2, Valery K. Shakurov', Raushan I. Aglyamov'
}

${ }^{1}$ Republican Clinical Oncological Dispensary, 73/1 Prospect Oktyabrya st., Ufa, 450054, Russian Federation

${ }^{2}$ Bashkir State Medical University, 3 Lenin st., Ufa, 450008, Russian Federation

Khrizman Yuriy Nusinovich - Candidate of Medical Sciences, Head of the Urology Department at №7 Republic Clinical Oncology Hospital, oncologist-urologist, e-mail: khrizmanyui@onkorb.ru

Gantsev Kamil Shamilevic - Doctor of Medical Sciences, Professor of the Oncology Department in BSMU, Oncologist in the Urology Department at №7 Republic Clinical Oncology Hospital, e-mail: gantseff@mail.ru

Safiullin Ruslan Ilyasovich - Doctor of Medical Sciences, Professor of the Urology Department in BSMU, Oncologist-urologist in the Urology Department at №7 Republic Clinical Oncology Hospital, e-mail: russafiullin@rambler.ru

Khmelevskiy Andrey Anatolevich - Postgraduate at the Oncology Department in BSMU, Oncologist in the Urology Department at №7 Republic Clinical Oncology Hospital, e-mail: larotos@mail.ru Shakurov Valeriy Kamilevich - Oncologist in the Urology Department at №7 Republic Clinical Oncology Hospital, e-mail: hakurovv@rambler.ru

Aglyamov Raushan Ilyasovich - Oncologist-urologist in the Urology Department at №7 Republic Clinical Oncology Hospital, e-mail: au-

aglymov@yandex.ru

Contacts: Khmelevsky Andrey, e-mail: larotos@mail.ru

Purpose of the study. Study of the nearest results of laparoscopic operations in patients with localized renal cell carcinoma.

Materials and methods. The results of treatment of 92 patients who underwent operative treatment in the period from 2015 to 2017 with the help of laparoscopic technique for kidney carcinoma were analyzed and evaluated. Of these, 57 men (62\%) and 35 women (38\%), the average age is $50.5 \pm 2.25$ years (min. 26 and not more than 75 years).

Results. The duration of the operation was influenced by various factors, such as the features of the vascular anatomy of the kidneys, the presence of the adhesive process of the abdominal cavity, the state of paranephalic fat. When improving the technique of performing laparoscopic interventions, the operation time was reduced. In the period of mastering the technique of laparoscopic interventions on the kidney, the operation time averaged $210.0 \pm 20.2 \mathrm{~min}$ ( $\mathrm{min} 120$ and $\max 300 \mathrm{~min}$ ); subsequently it decreased on average to $130.00 \pm 10.5 \mathrm{~min}$ ( $\mathrm{min} 70$ and $\mathrm{max} 190 \mathrm{~min}$ ). After accumulation of experience, the technique of laparoscopic resection of the kidney without total ischemia with selective clamping of segmental arteries, or without compression of the renal artery was mastered.

The conclusion. An analysis of the immediate results of laparoscopic interventions in patients with renal cell carcinoma showed their high efficacy and safety. The results of laparoscopic nephrectomies and kidney resections significantly improve with the improvement of technology and the accumulation of surgical experience.

Keywords: nephrectomy, laparoscopy, laparoscopic resection of the kidney, kidney neoplasms

For citation: Khrizman Yu.N., Gantsev K.Sh., Safiullin R.I., Khmelevsky A.A., Shakurov V.K., Aglyamov R.I. Experience of laparoscopic surgery in the treatment of renal cell cancer on the basis of the Republican clinical oncological dispensary. Creative surgery and oncology. 2017;7(4):48-52. DOI:10.24060/2076-3093-2017-7-4-48-52. 


\section{ВВЕДЕНИЕ}

Заболеваемость почечно-клеточным раком (ПКР) с каждым годом неуклонно растет и уступает по этому уровню лишь раку предстательной железы среди злокачественных новообразований мочеполовой системы $[1,2,3]$. Совершенствование диагностических методик, повышение их доступности, проведение плановых ежегодных осмотров и диспансеризаций населения неминуемо ведут к росту количества пациентов, нуждающихся в специализированном лечении. ПКР отличается тем, что длительное время может протекать бессимптомно. Единственным эффективным методом лечения рака почки является хирургический. Объем хирургического вмешательства всегда зависит от стадии, в которой рак был обнаружен [4]. Активное внедрение современных технологий, безусловно, является приоритетным направлением практической медицины. С каждым годом появляются новые разработки и методики, видоизменение и совершенствование которых всегда направлено на максимальное улучшение конечного результата $[5,6]$. Неоценимо важными являются умение специалиста использовать появившиеся инновации, обладание необходимым базисом знаний, а также способностью обучаться и приспосабливаться ко всем изменениям, происходящим во время непрекращающегося технического прогресса [7,8,9].

Внедрение лапароскопических методик в хирургию в начале 90-х годов прошлого столетия трудно переоценить. Малая инвазия, снижение травматизма и лекарственной нагрузки во время операции, малая кровопотеря, существенное сокращение сроков послеоперационного периода и пребывания пациента в стационаре - эти очевидные преимущества во многих случаях заменили потребность в выполнении открытых вмешательств как за рубежом, так и во многих регионах нашей страны $[10,11,12]$.

Относительным недостатком в сложившихся условиях является финансовый аспект данной лапароскопической методики. Высокая стоимость основного оборудования, расход одноразовых изделий, а также необходимость обучения персонала - вот то, что по-прежнему препятствует широкому повсеместному внедрению лапароскопии, которую уже можно считать «золотым стандартом» в оперативной урологии $[6,7,13]$

В урологическом отделении Республиканского клинического онкологического диспансера (РКОД) на протяжении последних лет активно осваивается и внедряется лапароскопическая хирургия верхних мочевых путей. Неоценимую методическую и практическую помощь оказал профессор кафедры урологии БГМУ Р.И. Сафиуллин. В этой статье мы обобщаем наш скромный опыт.

\section{МАТЕРИАЛЫ И МЕТОДЫ}

Выполнен ретроспективный анализ результатов лечения 92 пациентов, оперированных по поводу ПКР в условия урологического отделения РКОД за период с 2015 по 2017 гг. Из них 57 мужчин (62\%) и
35 женщин (38\%), средний возраст 50,5 $\pm 2,25$ года ( $\min 26$ и max 75 лет). Всем пациентам до операции проводилось комплексное обследование, включающее в себя проведение ультразвуковой диагностики, а также компьютерную томографию (КТ) сосудов почки с целью визуализации анатомических особенностей кровоснабжения почки. В 5-ти случаях пациенты были обследованы с использованием ПЭТ-КТ (позитронно-эмиссионная томография) [3].

При выполнении лапароскопических вмешательств использовались следующие виды операций:

1) Лапароскопическая радикальная нефрэктомия (с извлечением препарата через разрез по Пфаненштилю или по уже имеющемуся послеоперационному рубцу) - 40 пациентов. В 28 случаях пациенты имели 1 стадию заболевания (Т1а - опухоль до 4 см в диаметре и Т1b - опухоль от 4 до 7 см в диаметре). В 10 случаях - 2-ю стадию заболевания (Т2 - опухоль более 7 см в диаметре). В двух случаях 3-ю стадию заболевания (Т3 - прорастание опухоли за капсулу почки в паранефральную клетчатку установлено морфологически после оперативного вмешательства). На этапах освоения лапароскопические нефрэктомии проводились с помощью ручной ассистенции. В последующем с совершенствованием техники выполнения операции данная методика не использовалась (рис. 1).

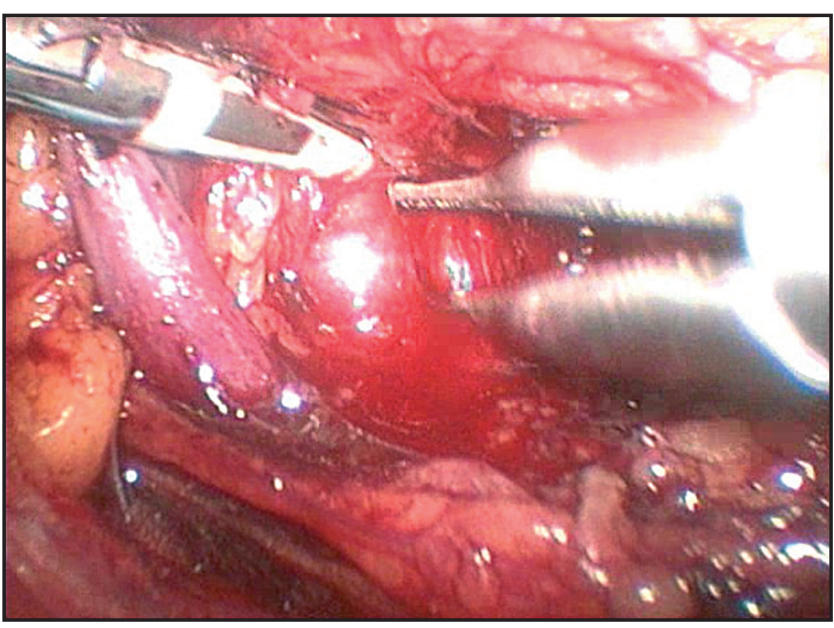

Рисунок 1 - Клипирование почечной артерии. Figure 1 - Clipping of the renal artery.

2) Лапароскопическая резекция почки - 52 пациента. Во всех случаях выполнения лапароскопической резекции почки пациенты имели 1-ю стадию заболевания: Т1a - 37 пациентов, Т1b - 15 пациентов.

В 2 случаях при дооперационном планировании пациента на резекцию почки с Т2 стадией интраоперационно принималось решение в пользу проведения нефрэктомии (рис. 2,3). 


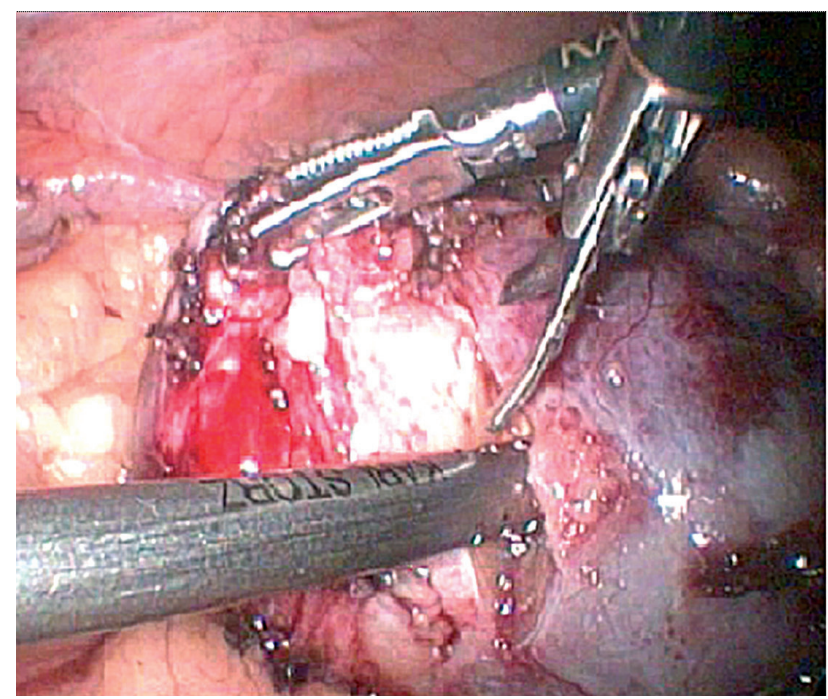

Рисунок 2 - Резекция почки холодными ножницами. Figure 2 - Partial nephrectomy with cold scissors.

\section{РЕЗУЛЬТАТЫ}

В период освоения методики лапароскопических вмешательств на почке время операции в среднем составляло 210,0 20,2 мин ( $\min 120$ и max 300 мин), в последующем оно составило в среднем

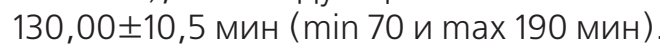

Из интра- и послеоперационных осложнений зарегистрированы следующие случаи:

1) в одном случае после резекции почки развилось кровотечение, потребовавшее реоперацию по остановке кровотечения;

2) однократно имело место развитие пареза кишечника, разрешенного консервативно;

3) в одном случае произошло повреждение мочеточника, потребовавшее интраоперационное стентирование мочеточника;

4) в двух случаях отмечалось повреждение полостной системы почки, распознанное в ходе операции, в связи с чем было выполнено интраоперационное ушивание дефекта;

5) после ЛПС-нефрэктомии зарегистрирован случай пареза кишечника, разрешившийся консервативно;

6) на этапе освоения в трех случаях была выполнена конверсия.

Вышеперечисленные осложнения практически не отразились на времени пребывания пациентов в стационаре и не имели отдаленных негативных результатов.

Всем пациентам выполнялись стандартные реабилитационные мероприятия.

Необязательным становилось пребывание пациента в палате реанимации после оперативного вмешательства. В некоторых случаях за счет крайне небольшой раневой поверхности болевой синдром не был выражен и не требовал медикаментозного купирования. На следующие сутки пациент мог без затруднений самостоятельно передвигаться по урологическому отделению.

Следует отметить, что во всех случаях послеоперационный период протекал у пациентов гладко.

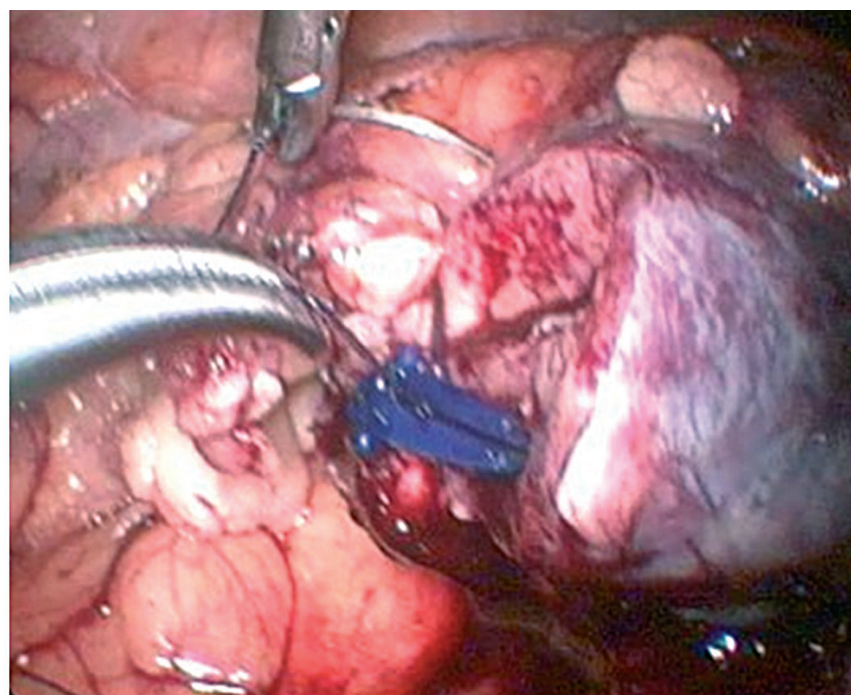

Рисунок 3 - Ушивание резецированного участка. Figure 3 - Suturing the resected area.

Средний период пребывания в стационаре, после которого пациента можно было бы выписать под наблюдение онколога по месту жительства, сократился до 6-7 дней (против 14 после открытых вмешательств), однако в связи с необходимостью выполнения стандартов фактический срок пребывания пациента в стационаре остался неизменным. После выписки повторных обращений в стационар по поводу осложнений зарегистрировано не было.

На момент написания статьи имеются достоверные данные об отсутствии рецидива заболевания по всем описанным случаям. Ввиду небольшого промежутка наблюдения оценить пятилетнюю выживаемость пока не представляется возможным.

\section{ОБСУХДЕНИЕ}

Таким образом, крайне низкий процент интра- и послеоперационных осложнений в сочетании с более легко переносимым для пациента периодом реабилитации говорит сам за себя. Однако следует понимать, что достижение положительного результата строится на совокупности множества факторов, как описанных в начале статьи, так и на этапе диагностики и планирования. Республиканский онкологический диспансер имеет все возможности современной диагностики - от проведения УЗИ, МРТ, КТ исследований до ПЭТ-КТ. Именно на диагностическом этапе разрабатывается план по выбору хирургической методики с индивидуальным подходом к каждому случаю. Далеко не всегда использование лапароскопических методик абсолютно оправдано. Важны правильное стадирование заболевания, оценка размеров опухоли, ее расположение и распространение, заинтересованность окружающих структур, а также анатомия прохождения основных сосудов. Не стоит забывать и об индивидуальных особенностях каждого пациента. Так, к примеру, при небольших опухолях почки лапароскопическая резекция однозначно имеет все преимущества перед открытой операцией, однако при крупных опухолях необходимость дополнительного разреза для их извлечения сводит эти преимущества к минимуму $[8,14,15]$. 


\section{ЗАКЛЮЧЕНИЕ}

Использование более современного оборудования, а также более совершенных инструментов является необходимым условием для достижения самых высоких хирургических задач. Умение идти в ногу со временем и способность к саморазвитию и созиданию - это те качества, которыми должен обладать каждый специалист. Но недвижимым фундаментом всегда были и будут понимание и индивидуальный подход к каждому случаю. Этап планирования операции, включающий в себя совокупность всех факторов, основанный на многолетнем удачном и неудачном опыте ведущих специалистов является тем, без чего обучение чему-то принципиально новому становится практически невозможным. Накопление опыта является важнейшим условием улучшения ближайших и отдаленных результатов хирургического лечения.

Информация о конфликте интересов. Конфликт интересов отсутствует.

Информация о спонсорстве. Данная работа не финансировалась.

\section{CПИСОК ЛИТЕРАТУРЫ/REFERENCES}

1. Рич Д.П., Д'Амико Э.В. Онкоурология. М.:БИНОМ;2011:896 с. [Rich D.P., D’Amico E.V. Oncourology. M.:BINOM;2011:896 p. (in Russ.)].

2. Одилов А.Ю., Кадыров 3.А., Нусратуллоев И.Н., Багдасарян А.А. Лапароскопические методы нефрэктомии при объёмных образованиях почек. Вестник Авиценны. 2013;4 (57):111-118. [Odilov A.Yu., Kadyrov Z.A., Nusratulloev I.N., Bagdasarian A.A. Laparoscopic methods of nephrectomy in renal spaceoccupying lesions. Vestnik Avitsenni. 2013;4 (57):111118 (in Russ.)]

3. Матвеев Б.П. (ред.) Клиническая онкоурология. М.:АБВ-пресс;2011:934 с. [Matveev B.P. (ed.) Clinical Oncourology. M.:ABV-press;2011:934 p. (in Russ.)].

4. Димитриади С.Н. Новые возможности проведения лапароскопической резекции почки по поводу почечно-клеточного рака с вовлечением чашечно-лоханочной системы. Известия высших учебных заведений. Северо-Кавказский регион. Сер.: Естественные науки. 2014;(4):82-86. [Dimitriadi S.N. New opportunities of performing of laparoscopic partial nephrectomy in patients with renal cell carcinoma involving pelvicaliceal system. University news. North-caucasian region. Natural sciences series. 2014; (4):82-86 (in Russ.)].

5. Кит О.И., Димитриади С.Н. Оценка клинической эффективности модифицированной методики лапароскопической резекции почки. Медицинский вестник Башкортостана. 2013;8(2):300-301. [Kit O.I., Dimitriadi S.N. Clinical effectiveness assessment of modified method of laparoscopic partial nephrectomy. Bashkortostan Medical Journal. 2013;8(2):300-301 (in Russ.)].

6. Попов С.В., Гусейнов Р.Г., Борисенков М.Б., Новиков А.И., Скрябин О.Н., Орлов И.Н., и др. Сравнительная оценка выживаемости пациентов с раком почки после эндовидеохирургической радикальной нефрэктомии и резекции почки. Онкоурология 2013; (2):21-25. [Popov S.V., Guseinov R.G., Borisenkov M.B., Novikov A.I., Skryabin O.N., Orlov I.N., et al. Comparative survival evaluation in patients with kidney cancer after endovideosurgical radical nephrectomy and renal resection. Oncourologiya $=$ Cancer Urology. 2013;9(2):21-25 (in Russ.)]. DOI: 10.17650/1726-97762013-9-2-21-25.

7. Димитриади С.Н., Кит О.И., Медведев В.Л. Технические особенности выполнения лапароскопи ческой резекции почки при почечно-клеточном раке. Онкоурология. 2014;10(2):16-21. [Dimitriad S.N., Kit O.I., Medvedev V.L. Technical characteristics of laparoscopic partial nephrectomy in case of renal cell carcinoma. Oncouroloiya=Cancer Urology. 2014;10(2):16-21 (In Russ. )]. DOI:10.17650/1726-9776-2014-10-2-16-21.

8. Носов А.К., Лушина П.А., Петров С.Б., Воробьев А.В., Калинин П.С., Мищенко А.В. Сравнение лапароскопической резекции почки при опухолевом поражении с наложением и без наложения гемостатического шва. Вопросы онкологии. 2017;63(2):281-286. [Nosov A.K., Lushina P.A., Petrov S.B., Vorobiev A.V., Kalinin P.S., Mishchenko A.V. Comparison of laparoscopic resection of the kidney in renal tumors with and without the application of a hemostatic suture. Voprosy onkologii=Problems in oncology. 2017;63(2):281-286 (in Russ.)]

9. Mattar K., Finelli A. Expanding the indications for laparoscopic radical nephrectomy. Curr Opin Urol. 2007;17(2):88-92. DOI: 10.1097/ MOU.0b013e32802b7070.

10. Qing Yang, Jun Du, Zhi-Hua Zhao, Xu-Sheng Chen, Lei Zhou and Xin Yao. Fast access and early ligation of the renal pedicle significantly facilitates retroperitoneal laparoscopic radical nephrectomy procedures: modified laparoscopic radical nephrectomy. World J Surg Oncol. 2013;11:27. DOI:10.1186/1477-7819-11-27.

11. Godoy G., Ramanathan V., Kanofsky J.A., O’Malley R.L., Tareen B.U., Taneja S.S., et al. Effect of warm ischemia time during laparoscopic partial nephrectomy on early postoperative glomerular filtration rate. J Urol. 2009;181(6):2438-43. DOl: 10.1016/j.juro.2009.02.026.181:2438-43.

12. Hung A.J., Cai J., Simmons M.N., Gill I.S. «Trifecta» in partial nephrectomy. J Urol. 2013;189(1):36-42. DOI: 10.1016/j.juro.2012.09.042.

13. Zabell J.R., Wu J., Suk-Ouichai C., Campbell S.C. Renal ischemia and functional outcomes following partial nephrectomy. Urol Clin North Am. 2017;44(2):243-255. DOI: 10.1016/j.ucl.2016.12.010.

14. Lu Yang, Tianyong Fan, Qiang Wei, Xiaobo Cui, Siyuan Bu, Ping Han. Transient variations in the serum concentrations of cell adhesion molecules following retroperitoneal laparoscopic and open radical nephrectomy for localized renal-cell carcinoma. J Endourol. 2012;26(10):1323-28. DOI:10.1089/ end.2011.0673.

15. Filson Ch.P., Banerjee M., Wolf Jr. J.S., Zaojun Ye, Wei J.T., Miller D.C. Surgeon characteristics and long-term trends in the adoption of laparoscopic radical nephrectomy. J Urol. 2011;185(6): 2072-77. DOl:10.1016/j.juro.2011.02.057. 